\title{
Anti-vascular endothelial growth factor antibody single therapy for pancreatic neuroendocrine carcinoma exhibits a marked tumor growth-inhibitory effect
}

\author{
KAZUHIKO KASUYA ${ }^{1}$, YUICHI NAGAKAWA ${ }^{1}$, MINAKO SUZUKI ${ }^{1}$, HIROAKI TANAKA ${ }^{2}$, \\ HIROSHI OHTA ${ }^{2}$, TAKAO ITOI ${ }^{3}$ and AKIHIKO TSUCHIDA ${ }^{1}$ \\ ${ }^{1}$ Department of Digestive Surgery, Tokyo Medical University; ${ }^{2}$ Department of Clinical Pharmacy, \\ Tokyo University of Pharmacy and Life Sciences; ${ }^{3}$ Department of Internal Medicine, Tokyo Medical University, Tokyo, Japan
}

Received June 21, 2011; Accepted July 15, 2011

DOI: $10.3892 /$ etm.2011.349

\begin{abstract}
At present, no effective chemotherapy for pancreatic neuroendocrine carcinoma (PNEC) exists. However, anti-angiogenic therapy is expected to be effective for PNEC, a hypervascular tumor. We treated PNEC and hypovascular pancreatic ductal cell carcinoma (DCC) cell lines with the anti-vascular endothelial growth factor (VEGF) antibody bevacizumab, and compared the antitumor effect between the two different types of cell lines. The PNEC cell line QGP-1 and the DCC cell lines BxPC-3 and AsPC-1 were used. We evaluated the ability of the cell lines to proliferate and secrete VEGF in vitro, the antitumor effect of bevacizumab administration in vivo and the side effects of bevacizumab on the pancreas in a caerulein-induced pancreatitis model. Comparison of the QGP-1 and DCC cell lines showed that QGP-1 secreted a higher level of VEGF under a hypoxic environment than the DCC cell line, and bevacizumab exerted the most marked growth-inhibitory effect on QGP-1; the number of intratumoral blood vessels decreased and the percentage of proliferating cells was approximately the same. In the pancreatitis model, bevacizumab administration did not adversely affect the pancreatitis or the associated hypoxic environment. Bevacizumab does not affect the pancreas itself; therefore, its potent inhibitory effect on the growth of pancreatic neuroendocrine tumors alone can be expected.
\end{abstract}

\section{Introduction}

Curative resection of functional pancreatic neuroendocrine tumors (PNETs) is increasingly being performed due to advances in early diagnosis based on hormone-induced symp-

Correspondence to: Dr Kazuhiko Kasuya, Department of Digestive Surgery, Tokyo Medical University Hospital, 6-7-1 Nishishinjuku, Shinjukuku, Tokyo 167-0023, Japan

E-mail: kasuya-k@jcom.home.ne.jp

Key words: vascular endothelial growth factor, antibody, pancreas, neuroendocrine tumor toms and blood hormone measurement, as well as advances in localization techniques, such as the selective arterial secretagogue injection test and secretin receptor scintigraphy (1). In addition, sustained-release octreotide preparations have been found to alleviate the symptoms of functional PNETs and suppress tumor growth $(2,3)$. On the other hand, nonfunctional PNETs are often detected incidentally by imaging studies, such as CT, or by symptoms due to pressure of the tumor on surrounding organs. These tumors usually exhibit slow growth, but some of them may be pancreatic neuroendocrine cell carcinoma (PNEC), a malignant tumor which metastasizes to the liver, even when the primary tumor is small. The survival time of patients with hepatic metastasis of PNEC has been reported to be within 5 years, and almost no chemotherapy is effective for metastatic unresectable PNEC $(2,4)$. Both functional and non-functional PNETs, including PNEC, are hypervascular tumors and are known to express angiogenic molecules (5). In addition, it has been reported that the serum levels of angiogenic cytokines increase in PNET patients (6-8). For these reasons, anti-angiogenic therapy is expected to be effective against PNEC (9-12). By contrast, anti-angiogenic therapy is ineffective in many patients with common ductal cell carcinoma (DCC) $(13,14)$, since DCC is a hypovascular tumor and because pancreatitis associated with pancreatic duct obstruction due to pancreatic cancer induces the secretion of growth and adhesion factors, making antiangiogenic therapy alone insufficient (15).

In this study, we compared PNEC and DCC cell lines regarding their vascular endothelial growth factor (VEGF) expression levels and the effects of treatment with the antiVEGF antibody bevacizumab (Avastin ${ }^{\circledR}$; Genentech, Inc., San Francisco, CA, USA). In addition, we investigated the influence of bevacizumab administration on pancreatitis and considered the possibility of anti-angiogenic therapy for PNEC.

\section{Materials and methods}

Cell lines and assays. The QGP-1 pancreatic neuroendocrine cell carcinoma cell line was purchased from the Japanese Collection of Research Bioresources (Osaka, Japan) (16-18), and the AsPC-1 and BxPC-3 human pancreatic ductal 
carcinoma cell lines were purchased from the American Type Culture Collection (Manassas, VA, USA). Cells were cultured at $37^{\circ} \mathrm{C}$ in RPMI-1640 (Gibco, Life Technologies Japan Ltd., Tokyo, Japan) supplemented with $10 \%$ fetal calf serum (Sigma, St. Louis, MO, USA) in a humidified atmosphere containing 5\% $\mathrm{CO}_{2}$. For the cell viability assay, cells were cultured in 96-well microplates for $24 \mathrm{~h}$ at a volume of $100 \mu \mathrm{l}(10,000$ cells/well) at $37^{\circ} \mathrm{C}$ in a humidified atmosphere of $5 \% \mathrm{CO}_{2}$. When the cells became adherent to the plates, the plates were transferred to an environment of either 1 or $20 \% \mathrm{O}_{2}$, and incubated for 1,2 and 3 days. To evaluate the cell viability in a hypoxic atmosphere, methyl-tetrazolium (MTT; 3[4,5-dimethyl-thiazoyl-2-yl]2,5diphenyl-tetrazolium bromide; Sigma) was used. Cells were cultured in 96-well microplates and irradiated for $24 \mathrm{~h} ; 10 \mu \mathrm{l}$ of MTT solution (5 mg of MTT/1 ml of phosphate-buffered saline) was added to each well, followed by incubation for $4 \mathrm{~h}$. Finally, $100 \mu \mathrm{l}$ of acid-isopropanol was added to each well to solubilize MTT formazan. After complete solubilization of the dye by vortexing the plate, the absorbance was read on an Immunoreader (Powerscan HT; DS Pharma Biomedical Co. Ltd., Osaka, Japan) at an optical density of $570 \mathrm{~nm}$. For the human VEGF (h-VEGF) enzyme (protein)-linked immunosorbent assay (ELISA), when the cells became adherent to the plate, the plates were transferred to an environment of either 1 or $20 \% \mathrm{O}_{2}$, and incubated for 1, 2 and 3 days. To evaluate the h-VEGF protein expression of these cancer cells in a hypoxic atmosphere, a cell-based ELISA of human total VEGF (R\&D Systems Inc., Minneapolis, MN, USA) was used. The fluorescence of $\mathrm{h}-\mathrm{VEGF}$ protein expression in the cells was normalized to that of the quantity of h-VEGF protein of a known level.

Pancreatitis and assays. Female ICL mice, weighing 20-25 g, obtained from Clea Japan Inc. (Tokyo, Japan), were treated with caerulein (Sigma), $50 \mu \mathrm{g} / \mathrm{kg}$ intraperitoneally (i.p.) every hour for 6-7 h twice a week, to induce edematous pancreatitis $(19,20)$. At predetermined time points during a 4-week period after the first caerulein injection, 5-9 mice were treated with bevacizumab or human IgG (Sigma) as a control. Mice were i.p. injected with pimonidasole hydrochloride $(60 \mathrm{mg} / \mathrm{kg})$ (Sigma), and the pancreases were removed $120 \mathrm{~min}$ later. Immunostaining for the detection of hypoxic cells was carried out with anti-pimonidasol Ab (Hypoxyprobe-1 Plus; Natural Pharmacia International, Inc., Belmont, MA, USA) (21). Initial weight of the whole pancreas was recorded, and a fresh sample $<10 \mathrm{mg}$ was obtained from the pancreatic portion. The fresh pancreas sample was incubated to release the collagen at a pepsin concentration of $1 \mathrm{mg} / \mathrm{ml}$ of $0.5 \mathrm{M}$ acetic acid at $4^{\circ} \mathrm{C}$. The amount of collagen of the pancreas was measured using Sircol Soluble Collagen Assay (Biocolor Ltd., Carrickfergus, Northern Ireland, UK). To evaluate mouse-VEGF (m-VEGF) protein and mouse-VEGF receptor 1 (m-VEGFR1) expression in the mice under a pancreatitis condition, Quantikine mouse VEGF immunoassay and mouse VEGF-R1 immunoassay (R\&D Systems) were used. The fluorescence of m-VEGF and $\mathrm{m}-\mathrm{VEGFR} 1$ protein expression in the cells was normalized to that of the quantity of these proteins of a known level.

Xenograft model and assay. Athymic female Balb/c-nu/nu nude mice (4-6 weeks old) were purchased from Clea Japan.
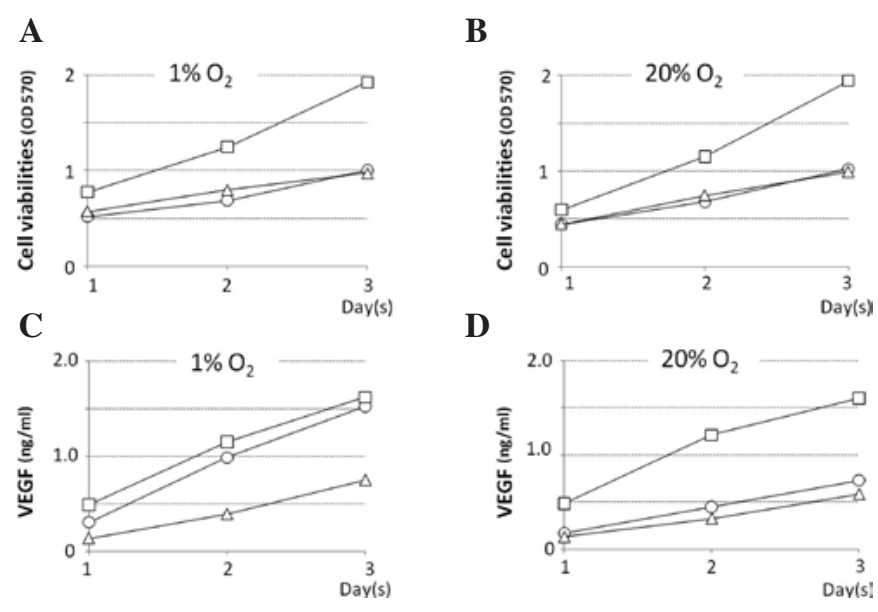

Figure 1. Cell viability under a (A) $1 \% \mathrm{O}_{2}$ and (B) $20 \% \mathrm{O}_{2}$ environment. $\mathrm{X}$-axis, time (in days). Y-axis, cell viability (absorbance). In all of the cell lines, the cell proliferation potency in an anoxia environment was the same as that in a normal oxygen environment. Level of VEGF $(\mathrm{ng} / \mathrm{ml})$ in the different culture mediums under a (C) $1 \% \mathrm{O}_{2}$ and (D) $20 \% \mathrm{O}_{2}$ environment. X-axis, time (in days). Y-axis, levels of VEGF (ng/mg). BxPc-3 (open squares), QGP-1 (open circles) and AsPC-1 (open triangles) cells. The VEGF secretional capacity of QGP-1 was increased in the anoxia environment.

The cell suspension of each cell line which was adjusted to a cell suspension $\left(2 \times 10^{7} \mathrm{cell} / \mathrm{ml}\right)$ in phenol red-free RPMI-1640 (Gibco) was mixed with Matrigel matrix (BD Biosciences, San Jose, CA, USA) on ice at a 1:4 ratio. The mixture was implanted subcutaneously into the back of the mice. The negative control group was injected with Matrigel alone $(n=2)$. Bevacizumab or human IgG (Sigma) was i.p. administrated twice a week from 7 to 28 days after cancer cell implantation. On day 28, each Matrigel and cancer cell mixture was removed and weighed, and the remaining gel was treated with Dispase II $(1.5 \mathrm{mg} / \mathrm{ml}$; Roche Diagnostics, Tokyo, Japan), followed by determination of the hemoglobin content using the Quantichrom hemoglobin assay kit (Gentaur, Kampenhout, Belgium). The remaining gel was immersed in $10 \%$ paraformaldehyde and embedded in paraffin. Sections were processed for immunostaining with H\&E, Ki-67 (MIB1; Dako Cytomation, Glostrup, Denmark) and CD34 (Abbiotec LLC, San Diego, CA, USA). Nine different fields representing areas with maximum microvessel content and number of Ki-67-positive cells were selected from each tumor. Necrotic areas were avoided. Regarding tumor characteristics, the number of microvessels with CD34positive vascular endothelial cells and the proliferative tumor cell ratio as determined by Ki-67-positivity [Ki-67 labeling index (LI)] were evaluated.

Statistical analysis. Statistical analyses were performed using Stat View (Abacus Concepts Inc., Berkely, CA, USA). The weight of the pancreas and the collagen weight/pancreas, as well as the number of microvessels, Ki-67 LI, hemoglobin content, volume and weight of the tumors were compared using the Mann-Whitney U test.

\section{Results}

Among the QGP-1, BxPC-3 and AsPC-1 cell lines, BxPC-3 exhibited the highest proliferation rate. The growth rate of 
Table I. Properties of the pancreatic cell lines.

\begin{tabular}{lccc}
\hline Variables & QGP-1 & BxPC-3 & AsPC-1 \\
\hline MTT & & & \\
Hypoxia & + & ++ & + \\
Normoxia & +++ & + & \\
VEGF protein expression & & & \\
Hypoxia & ++ & ++ & + \\
Normoxia $^{\text {a }}$ & + & ++ & + \\
\hline
\end{tabular}

${ }^{a} 20 \% \mathrm{O}_{2}$ environment; +, a response to criteria; ++, a higher response to criteria; +++ , the highest response to criteria.

all cell lines in normoxic and hypoxic environments was approximately the same (Fig. 1A and B). The level [accumulated during day(s) 1,2 and 3] of VEGF protein secreted in the culture supernatant of the BxP-3 cell line under normoxia was the highest, and these levels in the QGP-1 and AsPC-1 cell lines were approximately half. The levels of VEGF protein secreted in the culture supernatant of the QGP-1 cell line under normoxia were $135.3,359.1$ and $585.7 \mathrm{pg} / \mathrm{ml}$ on day(s) 1 , 2 and 3, respectively, but these levels were much higher under hypoxia, at 242.9, 789.8 and $1221.1 \mathrm{pg} / \mathrm{ml}$ on day(s) 1,2 and 3, respectively (Fig. 1C and D). The properties of the three cell lines are shown in Table I.

In mice with caerulein-induced pancreatitis, the serum VEGF levels at 1,2, 3 and 4 weeks after the start of caerulein administration were 162.7, 112.9, 96.7 and $114.5 \mathrm{pg} / \mathrm{ml}$, respectively, and those in the pancreatitis mice that received bevacizumab were $63.1,57.9,53.7$ and $117.1 \mathrm{pg} / \mathrm{ml}$, respectively. The serum VEGF level in the pancreatitis mice administered bevacizumab decreased to approximately half that $(57.9 \mathrm{pg} /$ $\mathrm{ml}$ ) in the normal mice in the second week or later (Fig. 2A). The serum VEGFR1 levels in the pancreatitis mice at 1, 2, 3 and 4 weeks after the start of caerulein administration were 319.4, below the detection limit, 1,062.2 and 1,314.8 pg/ml, respectively, and those in the pancreatitis mice receiving bevacizumab were somewhat higher, at 659.5, 587.0, 1,024.7 and $1,649.9 \mathrm{pg} / \mathrm{ml}$, respectively (Fig. 2B). Grossly, the pancreas of normal mice appeared yellowish, whereas that of pancreatitis mice was whitish and atrophic. The pancreas of the normal and pancreatitis mice (both groups were administered IgG for comparison to the group administered bevacizumab) weighed $142.5 \pm 13.5$ and $76.7 \pm 20.1(\mathrm{mg} \pm \mathrm{SD}$ ), respectively, and the latter value was significantly lower than the former (Fig. 3A). The collagen content in the pancreatitis mice was significantly lower, at $9.6 \mu \mathrm{g} / \mathrm{mg}$, compared to that of the normal mice $(28 \mu \mathrm{g} / \mathrm{mg}$; $\mathrm{p}=0.037$; Fig. $3 \mathrm{~B})$. Thus, edematous pancreatitis was identified. The mean pancreatic weights of the bevacizumab-administered normal and pancreatitis mice were 154.1 \pm 45.9 and 100.2 $\pm 46.6(\mathrm{mg} \pm \mathrm{SD})$, respectively (Fig. 3A) The collagen content in these mice was significantly lower; $13.0 \pm 6.0$ compared to that of the normal mice $[30.2 \pm 8.9(\mu \mathrm{g} /$ $\mathrm{mg} \pm \mathrm{SD}$ ); $\mathrm{p}=0.027$; Fig. 3B]. Thus, the pancreatic weight of the bevacizumab-administered mice was somewhat higher, but not significantly, suggesting that bevacizumab does not exacerbate pancreatitis. No areas of positive pimonidazole staining were
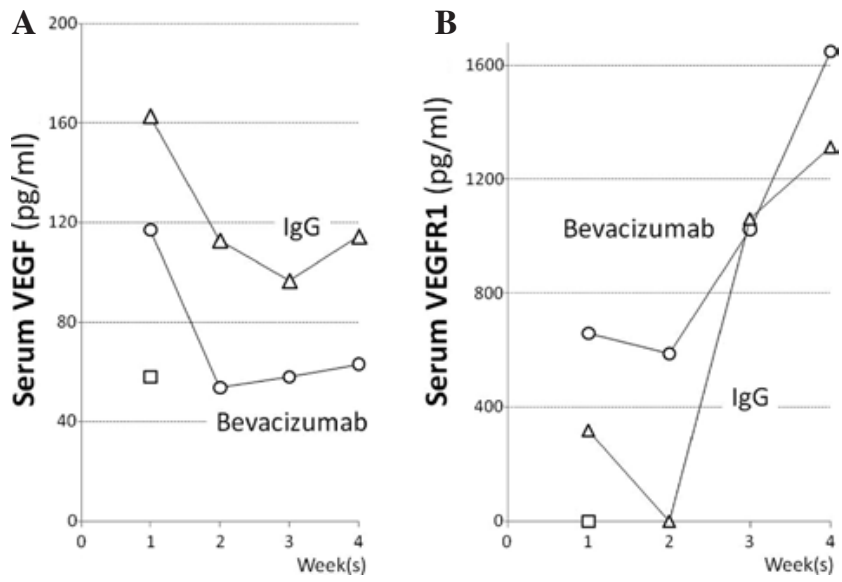

Figure 2. Levels of (A) VEGF and (B) VEGFR1 in the serum of the mice. $\mathrm{X}$-axis, time (in weeks). Y-axis, levels of VEGF (pg/mg) or VEGFR1 (pg/ml). Pancreatitis mice administered bevacizumab i.p. (open circles), mice administered human IgG i.p. as a control (open triangles) and normal mice (open squares).
A

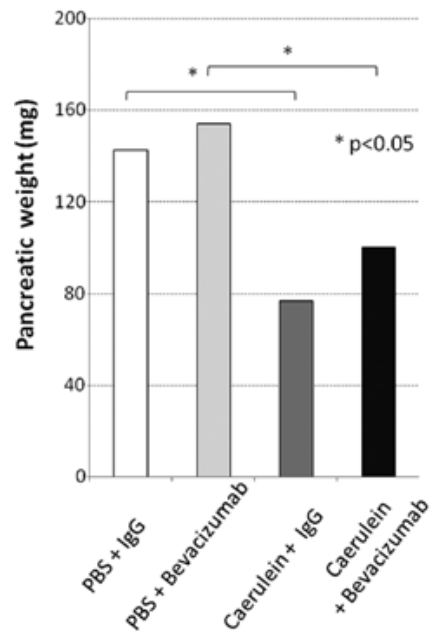

B

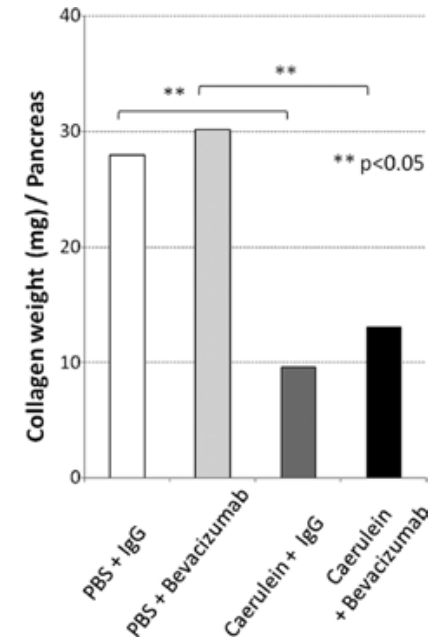

Figure 3. (A) Pancreatic weight and (B) component density of collagen. The pancreatic weight and its component density of collagen significantly decreased in the pancreatitis mice. These changes due to bevacizumab administration were slight. IgG-administered mice (white bar), bevacizumab-administered normal mice (light grey bar), IgG-administered mice with caerulein-induced pancreatitis (dark grey bar) and bevacizumab-administered mice with pancreatitis (black bar).

observed in the pancreas of the pancreatitis or normal mice, or the bevacizumab-administered mice (Fig. 4A-C). These results suggest that bevacizumab does not increase the area of ischemia in pancreatitis.

At autopsy, subcutaneous blood vessels overlying the tumor that were transplanted into the mice were grossly examined. Numerous subcutaneous blood vessels were overlying the reddish tumor in the $\mathrm{IgG}$-administered mice bearing the QGP-1, BxPC-3 or AsPC-1 cell lines (Fig. 5A and B), while few blood vessels were observed in the bevacizumab-administered mice (Fig. 5C and D). Intratumoral bleeding was noted in the IgG-administered, but not in the bevacizumab-administered mice bearing BxPC-3 cells (Fig. 5B). 

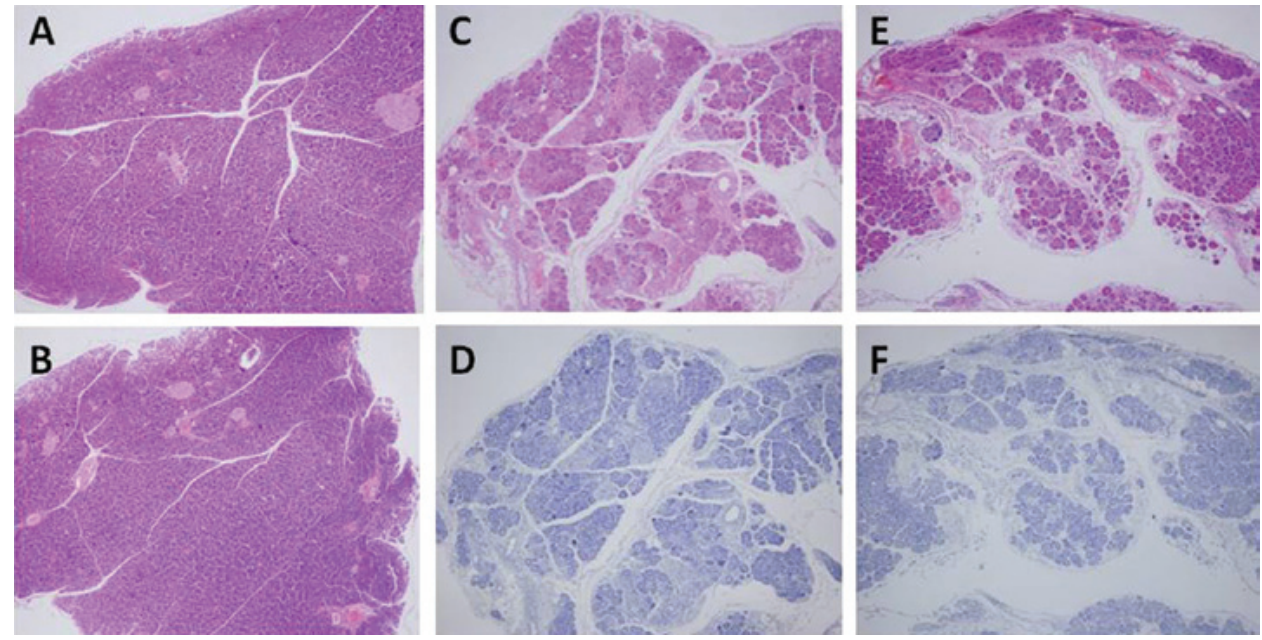

Figure 4. Histological findings of the pancreas. (A) IgG- and (B) bevacizumab-administered normal mice. (C and D) IgG- and (E and F) bevacizumabadministered mice with caerulein-induced pancreatitis. (A, B, C and E) H\&E staining; (D and F) pimonidasole staining.
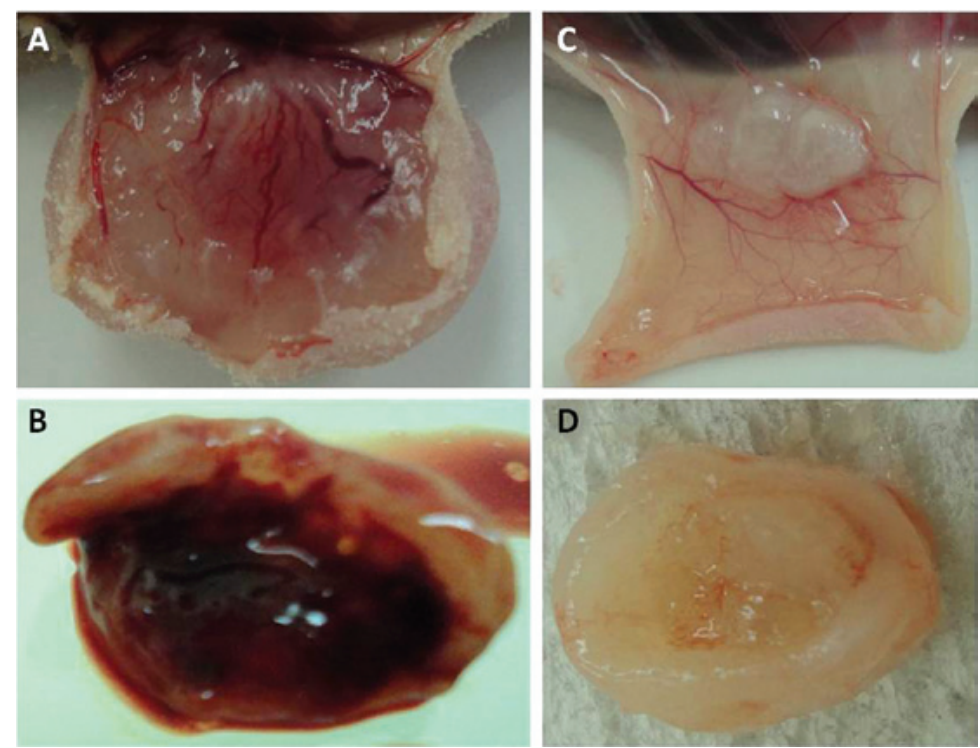

Figure 5. Macroscopic view of subcutaneous tumors. Tumor and subcutaneous tissue of IgG-administered mice bearing (A) QGP-1 and (B) BxPC-3 cells. Tumor and subcutaneous tissue of bevacizumab-administered mice bearing (C) QGP-1 and (D) BxPC-3 cells.
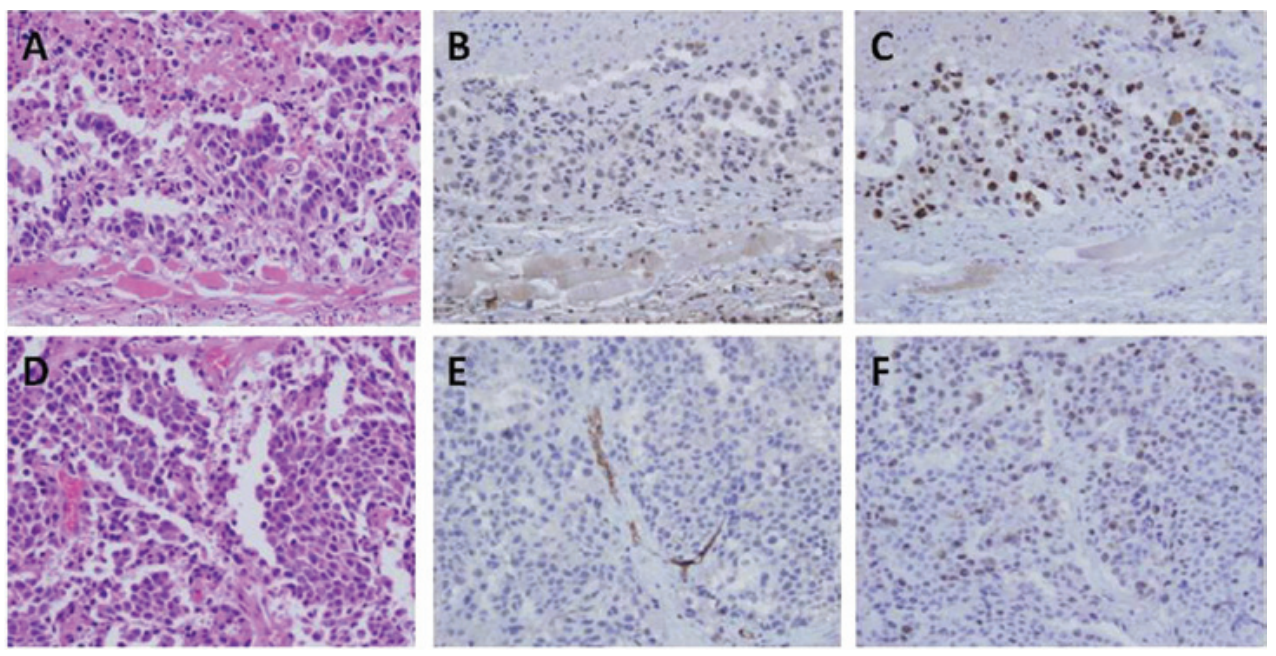

Figure 6. Tumor and subcutaneous tissue in (A-C) bevacizumab- and (D-F) IgG-administered mice bearing QGP-1 cells. (A and B) H\&E staining, (B and E) CD-34 staining and (C and F) Ki-67 staining. CD-34 immunoreactivity in the cancerous area in tumors of bevacizumab-administered mice was stronger than that of the $\mathrm{IgG}$-administered mice. 
Table II. Tumor characteristics.

\begin{tabular}{lrcc}
\hline Variables & QGP-1 & BxPC-3 & AsPC-1 \\
\hline $\begin{array}{l}\text { No. of CD34-positive cells/ } \\
\text { 9 high-power fields }\end{array}$ & & & \\
$\quad$ Bevacizumab & $5.0^{\mathrm{a}}$ & $12.5^{\mathrm{a}}$ & 1.6 \\
IgG & $27.0^{\mathrm{a}}$ & $28.0^{\mathrm{a}}$ & 3.2 \\
Ki-67 labeling index & & & \\
Bevacizumab & $34.4 \%$ & $26.4 \%$ & $35.2 \%$ \\
IgG & $37.3 \%$ & $33.3 \%$ & $47.0 \%$ \\
\hline
\end{tabular}

${ }^{\mathrm{a}} \mathrm{p}<0.05$

H\&E, CD34 and Ki-67 immunostaining of QGP-1 cells is shown in Fig. 6A-F. The tumor characteristics are described in detail in Table II. A significant difference in the number of CD34-positive microvessels for tumors composed of the QGP-1 and BxPC-3 cells was observed between the IgGand bevacizumab-administered groups while no significant difference was noted in the tumors consisting of AsPC-1 cells (Fig. 6; Table II). By contrast, there was no significant difference in the Ki-67 LI between the IgG- and bevacizumabadministered groups for all cell lines (Fig. 6; Table II). The hemoglobin levels in Matrigel (reflecting the intratumoral vascular bed) in the IgG-administered mice bearing QGP-1, BxPC-3 and AsPC-1 cells were 159.8, 50.4 and $27.1 \mathrm{mg} / \mathrm{dl}$, respectively, showing inter-cell-line differences, while these levels in their bevacizumab-administered counterparts were 72.7, 17.7 and $24.6 \mathrm{mg} / \mathrm{dl}$, respectively, which were lower than those in the IgG-administered mice (Fig. 7A; $\mathrm{p}=0.027$, $\mathrm{p}=0.037$ and no significant difference). The volume $\left(\mathrm{mm}^{3}\right)$ and weight $(\mathrm{mg})$ of the tumors composed of each cell line significantly decreased in response to therapy. The QGP-1 and BxPC-3 cell lines responded more strongly than the AsPC-1 cell line (Fig. 7B and C).

\section{Discussion}

Bevacizumab is a recombinant human IgG1 monoclonal antibody against VEGF; it specifically binds to VEGF in the bloodstream and inhibits the binding of VEGF to VEGF receptors (VEGFRs) in vascular endothelial cells, thereby inhibiting angiogenesis. The interstitial pressure around a tumor is usually increased, inhibiting the delivery of anticancer drugs to tumor tissue. Bevacizumab normalizes tumor blood vessels, reduces the interstitial pressure and thereby improves the delivery of anticancer drugs to tumor tissue $(10,11)$. In expectation of the added effect of combining bevacizumab with gemicitabine, a randomized controlled trial of gemicitabine + placebo vs. gemicitabine + bevacizumab for the treatment of advanced unresectable pancreatic cancer (CALGB80303) was conducted. However, no significant differences were observed between the gemicitabine + placebo and gemicitabine + bevacizumab groups in the therapeutic response rates (11 vs. $10 \%$, respectively), median progression-free survival times (4.9 vs. 4.7 months, respectively; $\mathrm{p}=0.99$ ) and median survival times (5.8 vs. 6.1 months, respectively; $\mathrm{p}=0.78$ ). Thus, gemicitabine + bevacizumab therapy did not prolong the survival time compared to gemicitabine therapy $(13,14)$.

K-ras mutations are found in nearly all pancreatic cancers. Possible reasons for the unresponsiveness of pancreatic cancers to drugs include K-ras gene mutations. However, in a randomized controlled trial of chemotherapy vs. chemotherapy + bevacizumab for the treatment of colorectal cancer with K-ras mutations, chemotherapy + bevacizumab prolonged the progression-free survival time by $69 \%$ in patients with K-ras mutations (5.5 vs. 9.4 months), and by $82 \%$ in those with the wild-type K-ras gene, that is without K-ras mutations (7.4 vs. 13.5 months) (22). No standard chemotherapy has been established for gastrointestinal neuroendocrine tumors. Somatostatin analogues are often used to alleviate the symptoms of neuroendocrine tumors (3), and their antitumor effects have been reported (23). In a randomized phase II trial of bevacizumab vs. interferon- $\alpha$ for the treatment of patients $(n=44)$ with unresect-
A

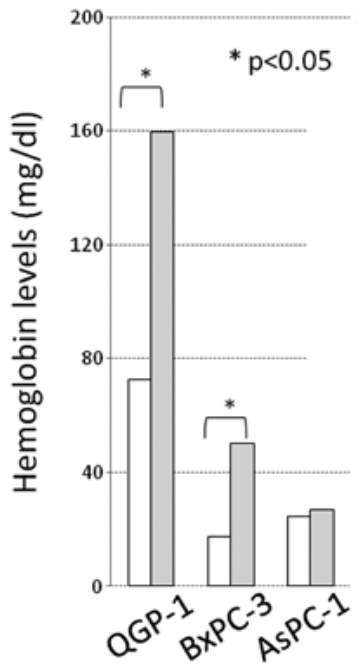

B

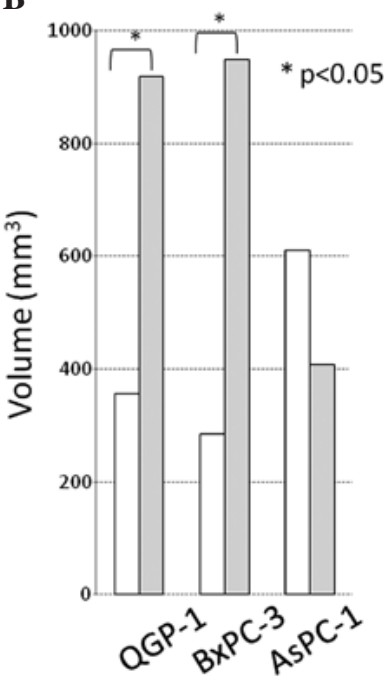

C

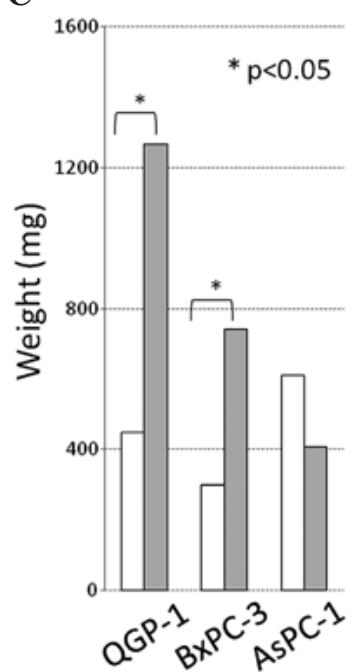

Figure 7. (A) Hemoglobin levels, (B) volume $\left(\mathrm{mm}^{3}\right)$ and $(\mathrm{C})$ weight $(\mathrm{mg})$ of the tumors. Tumors of bevacizumab-administered mice (white bar) and tumors of IgG-administered mice (grey bar). The hemoglobin levels, the volume and the weight of the tumors achieved significant differences between the bevacizumaband IgG-administered mice bearing QGP-1 and BxPC-3 cells. "p $<0.05$. 
able carcinoid tumors treated with octreotide, a somatostatin analogue, the added effect of combining bevacizumab with the somatostatin analogue was reported. The therapeutic response rates were 18 vs. $0 \%$, and the 8 -week progression-free survival rates were 95 vs. $68 \%$ (12). The effect of bevacizumab on PNEC alone has not been reported.

In many cases, pancreatic cancer is associated with pancreatitis, often with acute pancreatitis. Since bevacizumab has been reported to cause various adverse reactions by its vascular endothelial cell growth-inhibiting activity, there is concern that it may exacerbate the pancreatitis and promote fibrosis, as concomitant pancreatitis induces the release of various cytokines and clustering of fibroblasts, thereby resulting in the local invasion and distant metastasis of pancreatic cancer cells (15). In pancreatic cancer, VEGF and VEGFR are overexpressed $(7,8)$, but high serum VEGF levels are not only due to its secretion by cancer cells, but also often due to coexisting pancreatitis. Indeed, in the present mouse model of pancreatitis $(19,20)$, serum VEGF levels were higher than in normal mice. On the other hand, the weight and collagen content of the pancreas decreased, indicating that marked fibrosis as in pancreatitis coexisting with pancreatic cancer was not induced. The duration of caerulein administration was 4 weeks and the environment produced by pancreatitis may have been very limited; however, in this model histopathological examination showed no evidence of exacerbation of pancreatitis or promotion of fibrosis in the bevacizumab-administered group. These results mean that in pancreatitis coexisting with pancreatic cancers, including PNEC, bevacizumab administration does not induce pancreatitis or the associated hypoxic environment, or is not negatively involved.

A previous study confirmed the antitumor effect of ZM447439, which was found to simultaneously inhibit two members of the Aurora kinase family, Aurora A and B, in the QGP-1 PNEC cell line (17). Also, the use of cyclin-dependent kinase and the low-molecular-weight VEGFR inhibitor ZK304709 induced apoptosis (18). These are anticancer agents that target the cell cycle. In the present study, bevacizumab itself showed no cytotoxic effect, but only reduced the rate of tumor growth by inhibiting host angiogenesis. However, this effect was extremely strong, suggesting that drugs with potent cytotoxic activity, including the above-described anticancer agents, are important.

In conclusion, the PNEC cell line showed a higher secretion of VEGF than the DCC cell lines. Single therapy with the anti-VEGF antibody bevacizumab inhibited the induction of host angiogenesis in vivo, resulting in significant tumor growth inhibition, but not in tumor angiogenesis inhibition. In addition, bevacizumab reduced serum VEGF levels, but did not increase the area of ischemia in the pancreas. These results show that bevacizumab does not affect the pancreas itself, and it is expected to exert a potent growth-inhibitory effect on PNEC alone.

\section{References}

1. Eriksson B and Oberg K: Neuroendocrine tumours of the pancreas. Br J Surg 87: 129-131, 2000.

2. Modlin IM, Oberg K, Chung DC, et al: Gastroenteropancreatic neuroendocrine tumours. Lancet Oncol 9: 61-72, 2008.

3. Oberg KE, Reubi JC, Kwekkeboom DJ and Krenning EP: Role of somatostatins in gastroenteropancreatic neuroendocrine tumor development and therapy. Gastroenterology 139: 742-753, 2010.
4. Kazanjian KK, Reber HA and Hines OJ: Resection of pancreatic neuroendocrine tumors: results of 70 cases. Arch Surg 141: 765-769, 2006.

5. Takahashi Y, Akishima-Fukasawa Y, Kobayashi N, et al: Prognostic value of tumor architecture, tumor-associated vascular characteristics, and expression of angiogenic molecules in pancreatic endocrine tumors. Clin Cancer Res 13: 187-196, 2007.

6. Pavel ME, Hassler G, Baum U, Hahn EG, Lohmann T and Schuppan D: Circulating levels of angiogenic cytokines can predict tumour progression and prognosis in neuroendocrine carcinomas. Clin Endocrinol 62: 434-443, 2005.

7. Karayiannakis AJ, Bolanaki H, Syrigos KN, Asimakopoulos B, Polychronidis A, Anagnostoulis S and Simopoulos C: Serum vascular endothelial growth factor levels in pancreatic cancer patients correlate with advanced and metastatic disease and poor prognosis. Cancer Lett 194: 119-124, 2003.

8. Chang YT, Chang MC, Wei SC, et al: Serum vascular endothelial growth factor/soluble vascular endothelial growth factor receptor 1 ratio is an independent prognostic marker in pancreatic cancer. Pancreas 37: 145-150, 2008.

9. Pàez-Ribes M, Allen E, Hudock J, et al: Antiangiogenic therapy elicits malignant progression of tumors to increased local invasion and distant metastasis. Cancer Cell 15: 220-231, 2009.

10. Willett CG, Boucher Y, di Tomaso E, et al: Direct evidence that the VEGF-specific antibody bevacizumab has antivascular effects in human rectal cancer. Nat Med 10: 145-147, 2004

11. Jain RK, Duda DG, Clark JW and Loeffler JS: Lessons from phase III clinical trials on anti-VEGF therapy for cancer. Nat Clin Pract Oncol 3: 24-40, 2006.

12. Yao JC, Phan A, Hoff PM, et al: Targeting vascular endothelial growth factor in advanced carcinoid tumor: a random assignment phase 11 study of depot octreotide with bevacizumab and pegylated interferon alpha-2b. Clin Oncol 26: 1316-1323, 2008.

13. Kindler HL, Friberg G, Singh DA, et al: Phase II trial of bevacizumab plus gemcitabine in patients with advanced pancreatic cancer. J Clin Oncol 23: 8033-8040, 2005.

14. Kindler HL, Niedzwiecki D, Hollis D, et al: A double-blind, placebo-controlled, randomized phase III trial of gemcitabine (G) plus bevacizumab (B) versus gemcitabine plus placebo $(\mathrm{P})$ in patients (pts) with advanced pancreatic cancer (PC): a preliminary analysis of Cancer and Leukemia Group B (CALGB). J Clin Oncol 25 (Suppl 18): 4508, 2007.

15. Kuehn R, Lelkes PI, Bloechle C, Niendorf A and Izbicki JR: Angiogenesis, angiogenic growth factors, and cell adhesion molecules are upregulated in chronic pancreatic diseases: angiogenesis in chronic pancreatitis and in pancreatic cancer. Pancreas 18: 96-103, 1999.

16. Takahashi K, Hirano F, Matsumoto K, Aso K and Haneda M: Homeobox gene CDX2 inhibits human pancreatic cancer cell proliferation by down-regulating cyclin D1 transcriptional activity. Pancreas 38: 49-57, 2009.

17. Georgieva I, Koychev D, Wang Y, Holstein J, Hopfenmüller W, Zeitz M and Grabowski P: ZM447439, a novel promising aurora kinase inhibitor, provokes antiproliferative and proapoptotic effects alone and in combination with bio- and chemotherapeutic agents in gastroenteropancreatic neuroendocrine tumor cell lines. Neuroendocrinology 91: 121-130, 2010.

18. Scholz A, Wagner K, Welzel M, et al: The oral multitarget tumour growth inhibitor, ZK 304709, inhibits growth of pancreatic neuroendocrine tumours in an orthotopic mouse model. Gut 58: 261-270, 2009.

19. Neuschwander-Tetri BA, Burton FR, Presti ME, et al: Repetitive self-limited acute pancreatitis induces pancreatic fibrogenesis in the mouse. Dig Dis Sci 45: 665-674, 2000.

20. Carrière C, Young AL, Gunn JR, Longnecker DS and Korc M: Acute pancreatitis markedly accelerates pancreatic cancer progression in mice expressing oncogenic Kras. Biochem Biophys Res Commun 382: 561-565, 2009.

21. Liu J, Qu R, Ogura M, Shibata T, Harada H and Hiraoka M: Real-time imaging of hypoxia-inducible factor-1 activity in tumor xenografts. J Radiat Res 46: 93-102, 2005.

22. Hurwitz HI, Yi J, Ince W, Novotny WF and Rosen O: The clinical benefit of bevacizumab in metastatic colorectal cancer is independent of K-ras mutation status: analysis of a phase III study of bevacizumab with chemotherapy in previously untreated metastatic colorectal cancer. Oncologist 14: 22-28, 2009.

23. Panzuto F, di Fonzo M, Iannicelli E, et al: Long-term clinical outcome of somatostatin analogues for treatment of progressive, metastatic, well-differentiated entero-pancreatic endocrine carcinoma. Ann Oncol 17: 461-466, 2006. 